\title{
Características climáticas local e as implicações na saúde da população de Mossoró- RN: contribuições iniciais
}

\section{Local climatic characteristics and the implications on the health of the population of Mossoró-RN: initial contributions}

\author{
DOI: $10.46919 / \operatorname{archv2n3-035~}$
}

Recebimento dos originais: 01/01/2021

Aceitação para publicação: 31/03/2021

\author{
Ana Luiza Bezerra Da Costa Saraiva \\ Mestrado \\ Universidade do Estado do Rio Grande do Norte \\ Rua Almino Afonso, 478 - Centro - CEP.: 59610-210 - Mossoró Rio Grande do Norte \\ E-mail: ageopesquisadora@ hotmail.com
}

Cláudia Câmara Do Vale

Pós Doutorado

Universidade Federal do Espírito Santo

Av. Fernando Ferrari, 514 - Campus de Goiabeiras - CEP.: 29075-910 - Vitória - Espírito Santo

E-mail: camaravale@gmail.com

\section{Maria Elisa Zanella}

Pós doutorado

Universidade Federal do Ceará

Campus do Pici - Bloco 911 - CEP.: 60440-900 - Fortaleza - Ceará

E-mail: elisazv@terra.com.br

\section{RESUMO}

Em função da sua latitude e da baixa altitude, o município de Mossoró possui média de 2.700 horas anual de sol e diurnas anuais elevadas. As altas temperaturas, bem como os baixos valores de umidade relativa do ar encontrados nos períodos diurnos, principalmente nos meses mais secos, podem gerar desconforto térmico e causar problemas de saúde. Diante dessa realidade esse trabalho tem como objetivo principal identificar a relação existente entre as características climáticas de Mossoró-RN como o conforto térmico e os impactos negativos a saúde humana. Foi realizado um levantamento bibliográfico sobre os tema e trabalhos de coleta de dados em Mossoró por meio de entrevistas com 40 pessoas. Relacionado a influencia do forte calor sobre ao bem-estar e a saúde, uma parcela significativa de pessoas afirmaram sentir sintomas indesejável pelas altas temperaturas do ar e pela baixa umidade relativa do ar, principalmente entre às $11 \mathrm{~h}$ e 15h. É preocupante o número de pessoas que afirma não possuir nenhum hábito que busque driblas os efeitos negativos das altas temperaturas do ar, da baixa umidade relativa e da radiação solar.

Palavras-chave: Temperatura do ar, Umidade Relativa do ar, Saúde.

\begin{abstract}
Due to its latitude and low altitude, the municipality of Mossoró has an average of 2,700 annual hours of sunshine and high annual daytime hours. The high temperatures, as well as the low relative humidity values found during the day, especially in the driest months, can generate thermal discomfort and cause health problems. Given this reality, this work has as its main objective to identify the relationship between the climatic characteristics of Mossoró-RN, such as thermal comfort and negative impacts on human health. A
\end{abstract}


bibliographical survey was carried out on the theme and data collection works in Mossoró through interviews with 40 people. Related to the influence of strong heat on well-being and health, a significant portion of people reported feeling undesirable symptoms due to high air temperatures and low relative humidity, especially between 11:00 and 15:00. It is worrying the number of people who claim to have no habit that seeks to avoid the negative effects of high air temperatures, low relative humidity and solar radiation.

Keywords: Air Temperature, Relative Air Humidity, Health.

\section{INTRODUÇÃO}

Os seres humanos que residem, estudam, trabalham ou praticam esportes onde as temperaturas são muito elevadas, como é o caso das cidades tropicais, podem sofrer danos à saúde, sendo as crianças e os idosos os mais atingidos. Em áreas urbanas essa situação pode ficar mais grave, uma vez que "nos núcleos de grande edificação e acumulação de calor produz-se stress térmico que em clima tropical pode ser persistente, causando desconforto térmico que ultrapassa os limites de tolerância dos habitantes" (LOMBARDO, 1995, p. 18).

As altas temperaturas, bem como os baixos de umidade relativa do ar, podem gerar desconforto térmico, prejudicando o bem estar e a saúde da população (ANDRADE,2005). Sabe-se da importância da radiação solar para saúde humana, mas destaca-se que, em excesso, pode gerar danos a saúde, do envelhecimento da pele às diversas doenças, dentre elas o câncer de pele (OKUMO; VILELA, 2005).

A umidade do ar possui um importante papel para a saúde humana. A Organização Mundial da Saúde (2012) sinaliza que o teor de umidade indicado deve ser superior a 60\%. Abaixo desse valor, entre $60 \%$ e $30 \%$ é classificado como não recomendado a saúde. Inferior a 30\% significa estados que vão de Atenção à Emergência. Os principais problemas oriundos da baixa umidade relativa do ar são: complicações alérgicas e respiratórias devido ao ressecamento de mucosas; sangramento pelo nariz; ressecamento da pele; e irritação dos olhos (OMS, 2012).

Nos espaços urbanos, marcados por diferentes usos e ocupação da terra, os valores de umidade relativa do ar, temperatura do ar e temperatura da superficie coletados no mesmo intervalo horário em locais distintos de uma mesma cidade podem apresentar diferenças significativas, gerando níveis de conforto térmico diferentes (SARAIVA, 2014).

Investigar o comportamento dos elementos climáticos (temperatura do ar, umidade relativa do ar, vento, pressão atmosférica e radiação) ao longo do dia e ao longo do ano é de fundamental importância para compreender as características climáticas de um local.

Em função da sua latitude $05^{\circ} 11^{\prime} \mathrm{S}$ o município de Mossoró, localizado na porção oeste do estado do Rio Grande do Norte, recebe anualmente cerca de 2,5 vezes mais radiação solar que os polos, pois os raios solares chegam de forma direta e com ângulos solares concentrados. Assim apresenta apenas uma 
pequena variação anual na temperatura do ar. O período diurno, principalmente entre as $10 \mathrm{~h}$ e $15 \mathrm{~h}$, apresenta os mais altos valores de temperatura do ar e de radiação solar, ambos os elementos relacionados diretamente ao desconforto térmico humano. Considerando que o clima local é sazonalmente seco, as características climáticas locais são marcantes: altas temperaturas ao longo do ano, períodos de chuva concentrados poucos meses, baixos valores de umidade relativa do ar durante o período diurno, um longo período de insolação diária e altos valores de radiação solar anual (SARAIVA, 2014).

O clima de Mossoró é classificado como semiárido e possui as características: "regularidades térmicas e variabilidade pluviométrica anuais expressivas. O outono caracteriza-se por ser mais chuvoso (a média mensal de março e abril é de cerca de $180 \mathrm{~mm}$ ) e o inverno e a primavera, menos chuvosos (chegando a 5mm em novembro) (MENDONÇA; DANNI-OLIVEIRA, 2007, p. 162)”.

Saraiva (2020) realizou uma leitura do comportamento dos elementos climático do município de Mossoró e destacou 4 períodos ao longo do ano: Período Quente com Chuvas Esporádicas nos meses de dezembro e janeiro; Período Chuvoso com alternância de Tempos Ensolarados e Nublados nos meses de fevereiro, março, abril e maio; Período Ameno com Chuvas Esporádicas nos meses de junho, julho e agosto; Período Seco, Muito Quente com Ventos Fortes nos meses setembro, outubro e novembro. Investigar o comportamento dos elementos climáticos (temperatura do ar, umidade relativa do ar, vento, pressão atmosférica e radiação) ao longo do dia e ao longo do ano é de fundamental importância para compreender as características climáticas de um local.

Diante da realidade climática de Mossoró faz-se necessário a realização de pesquisas que objetivem investigar a relação entre as características climáticas locais como o conforto térmico e os possíveis problemas de saúde. As investigações dessa natureza são fundamentais para identificar os grupos humanos mais atingidos, os principais sintomas e as principais causas desse problema. Com informações dessa natureza são importantes, pois podem alicerçar metas e medidas que busquem construir um ambiente salubre para as pessoas.

\section{PROCEDIMENTOS EXECUTADOS}

Para esse trabalho foi realizado um levantamento bibliográfico sobre os temas centrais do trabalho. Foram utilizados artigos de revista, monografias/dissertações e livros.

Posteriormente, foram realizados trabalhos de coleta de dados climáticos em Mossoró e realizadas as entrevistas com a população sobre a relação das características climáticas local e os efeitos na saúde humana.

Para a coleta dos dados climáticos foi elaborado o seguinte roteiro:

$1^{\circ}$ fase: Definição tanto da área de estudo: Clima local de Mossoró-RN; quanto do subsistema do clima urbano (MONTEIRO,1976) a ser estudado: campo térmico; 


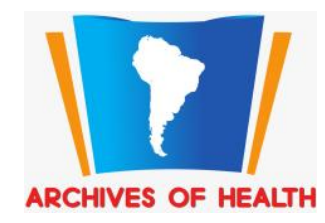

$2^{\circ}$ fase: Elaboração do embasamento cartográfico, utilizando SIG, com o objetivo de setorizar a cidade em ambientes geográficos diferenciados, para eleger os pontos de monitoramento de dados;

$3^{\circ}$ fase: Calibração dos Aparelhos. Monitoramento horário da variável temperatura do ar e umidade relativa do ar das $08 \mathrm{~h}$ às $17 \mathrm{~h}$ do dia 11/04/2012 em 6 pontos de coleta na área urbana (Figura 01) e 1 ponto na zona rural. Os aparelhos utilizados nos pontos da zona urbana foram o datalogger de temperatura e umidade (Impac - IP 747RH), que foram acomodados em abrigos meteorológicos de madeira de 1,50m de altura, pintados de branco e com espaços para circulação do ar na parte superior do abrigo onde os equipamentos ficavam instalados. Já o equipamento utilizado no ponto da zona rural é uma estação automática (Vaisala, MAWS 301), usadas como padrão para a rede de Estações Automáticas de Superfície (EMA) do INMET, onde são coletados dados de temperatura, umidade, pressão atmosférica, precipitação, direção e velocidade dos ventos e radiação solar (BRASIL, 2011).

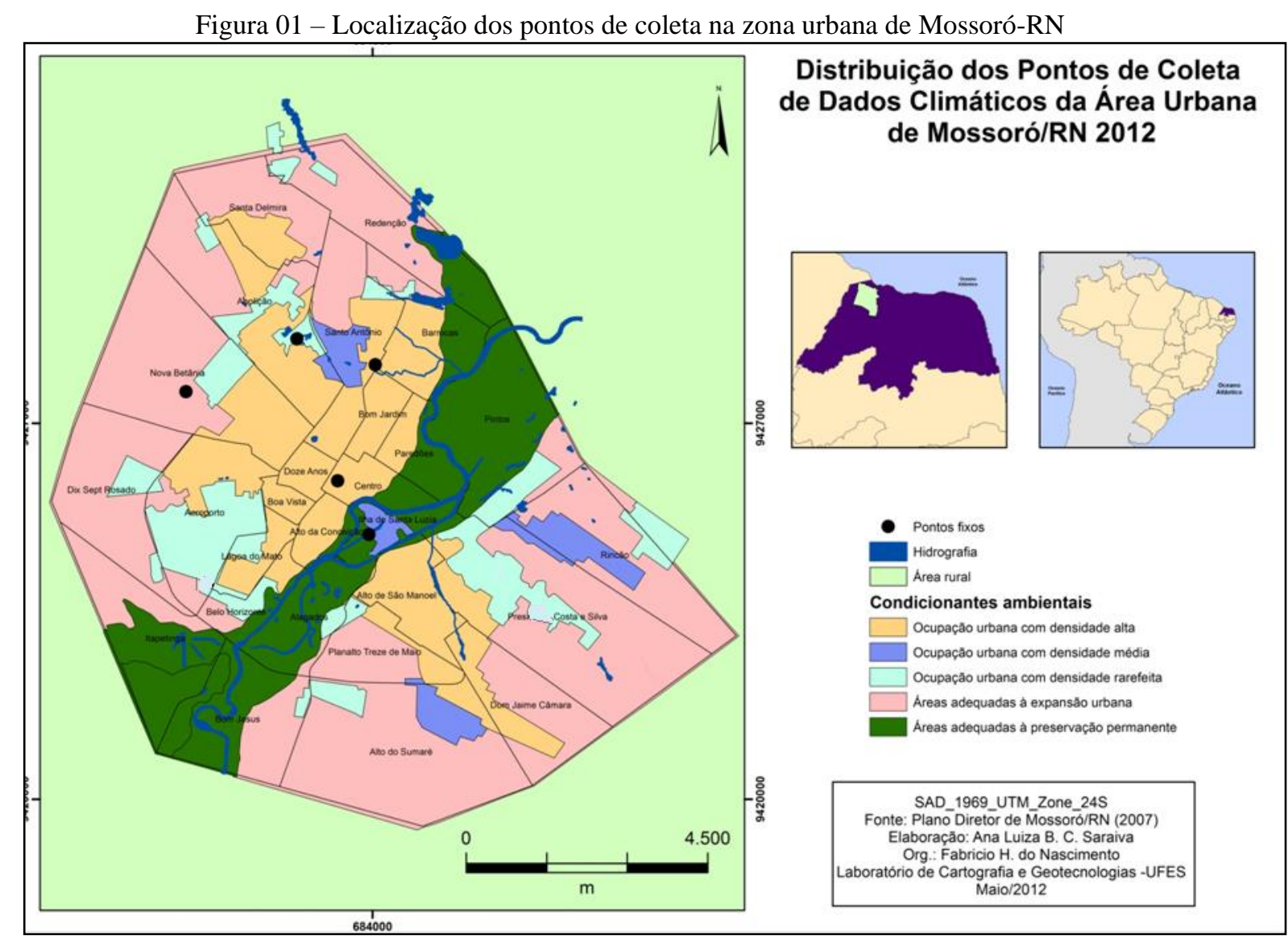

Fonte: Fonte dos dados: IBGE(2010), Plano Diretor de Mossoró (2007)

Organização: Nascimento e Saraiva (2014)

$4^{\circ}$ fase: Tabulação e análise dos dados coletados durante o monitoramento de campo.

$5^{\circ}$ fase: Formulação de sugestões relativas ao clima urbano de Mossoró-RN, com base nos resultados atingidos, na perspectiva do planejamento urbano. 
A entrevista elaborada para esse trabalho foi organizada em três blocos, sendo o $1^{\circ}$ bloco como questões destinadas à identificação da pesquisa, o $2^{\circ}$ bloco de questões referentes à identificação dos entrevistados e o $3^{\circ}$ bloco de questões centrada na relação existente entre os problemas de saúde relacionadas ao conforto e as medidas destinadas a diminuir os efeitos do desconforto térmico. As entrevistas foram realizadas em duas praças do centro urbano de Mossoró, pois por esses locais passam muitas pessoas diariamente. Posteriormente os dados foram organizados, tabulados e analisados.

Foram selecionados três critérios para a realização da pesquisa e escolha dos entrevistados dos bairros selecionados: $1^{\circ}$ - o entrevistado ou a entrevistada não poderia fazer parte dos integrantes da pesquisa; $2^{\circ}$ - o entrevistado ou a entrevistada deveria ser escolhido aleatoriamente pelo entrevistado; e $3^{\circ}$ - ter idade igual ou superior a 16 anos.

\section{RESULTADOS E DISCUSSÃO}

\subsection{CARACTERIZAÇÃO E DESCRIÇÃO DOS PONTOS SELECIONADOS PARA A COLETA DE DADOS CLIMÁTICOS:}

P01 - Bairro Ilha de Santa Luzia (Figura 2 e Figura 3): Localizada nas margens do rio Apodi Mossoró, dentro da área particular do Hotel VillaOeste. Possui poucas edificações nas proximidades. Relativo ao zoneamento urbano proposto pela Prefeitura está localizado em uma zona urbana de proteção ambiental, sendo classificada segundo os condicionantes ambientais como área adequada à preservação permanente. Nas proximidades desse ponto de coleta existem árvores e parte significativa do solo é recoberto por plantas herbáceas/arbustivas e por solo exposto.

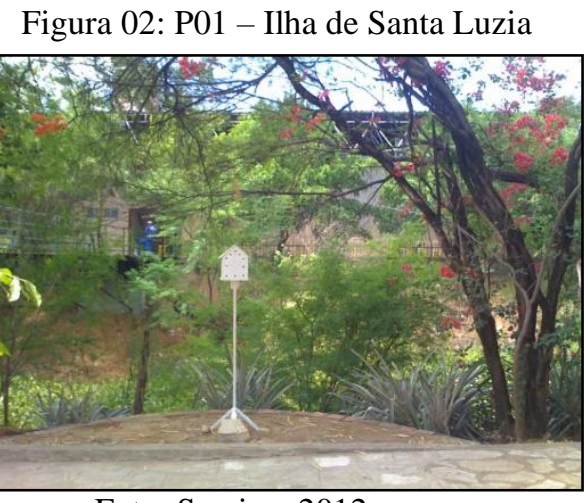

Foto: Saraiva, 2012
Figura 03: Localização do P01

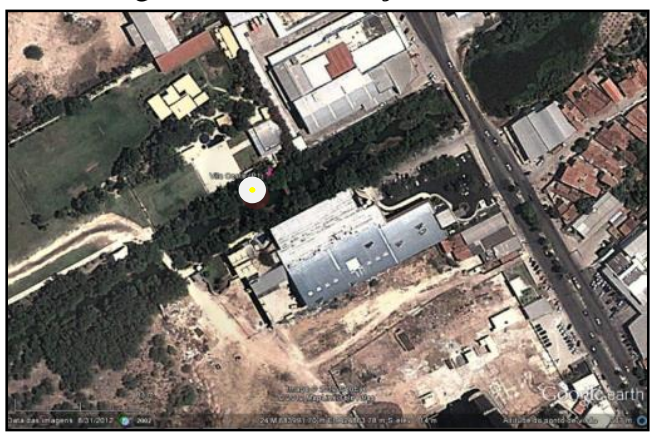

Fonte: Fonte: Google Earth@, 2012.

P02 - Bairro Centro (Figura 4 e Figura 5): É um bairro de alta densidade demográfica que, segundo o zoneamento proposto pela Prefeitura, localiza-se na área de especial interesse do centro, sendo que segundo a classificação das atividades econômicas é a principal zona comercial da cidade. Teve sua ocupação intensificada após a década de 1940. Nas proximidades existem diversos equipamentos urbanos: 


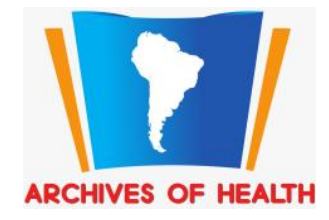

unidades de desenvolvimento cultural e social, unidades de saúde, unidades escolares e unidades de esporte e de lazer. Nas proximidades desse ponto de coleta existem poucas árvores e o solo ora é exposto, ora é asfaltado. Este abrigo meteorológico foi instalado no estacionamento da sede da Prefeitura Municipal de Mossoró sendo um local de grande fluxo de pessoas e veículos.

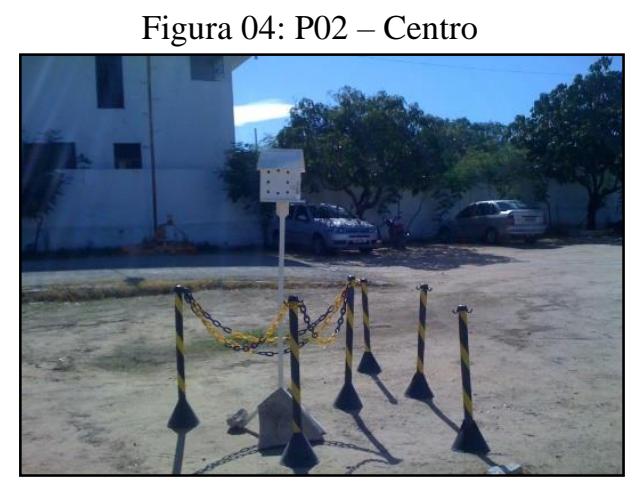

Foto: Saraiva, 2012.
Figura 05: Localização do P02

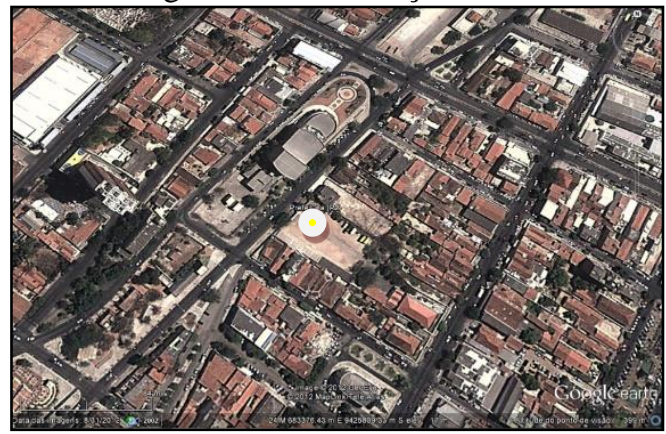

Fonte: Google Earth@, 2012.

P03 - Bairro Santo Antônio (Figura 6 e 7): Local próximo a avenida com grande fluxo de veículos e pessoas, devido a proximidade com um hospital público de emergência e com o centro da cidade. Possui casas residenciais e pontos comerciais. Relativo ao zoneamento urbano proposto pela PMM é uma zona predominantemente residencial uni familiar e multi familiar. Segundo o zoneamento das atividades econômicas é considerado zona residencial, que teve sua ocupação intensificada após 1975, sendo a ocupação urbana do bairro de alta densidade. Nas proximidades desse ponto de coleta existem poucas árvores e o solo é recoberto por concreto.

Figura 06: P03 - Santo Antônio

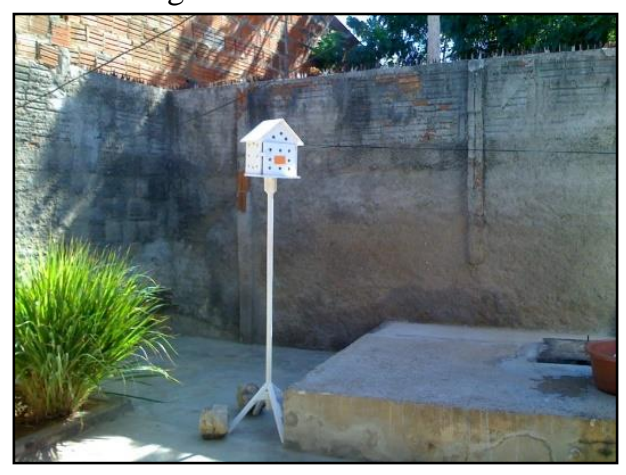

Foto: Saraiva, 2012.
Figura 07: Localização do P03

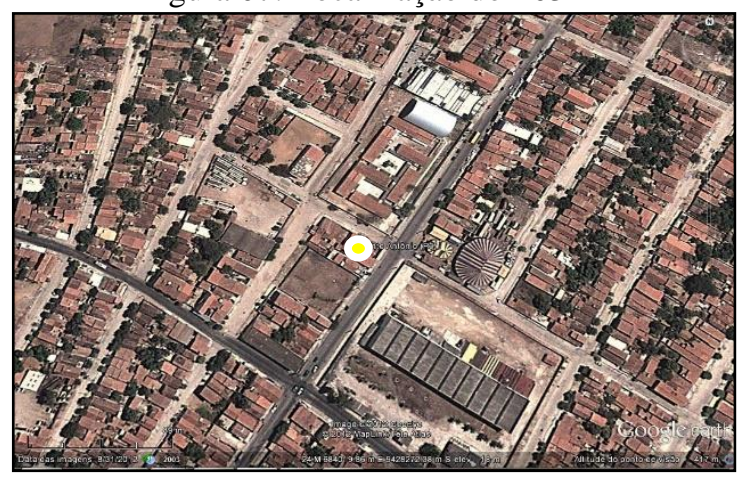

Fonte: Google Earth@, 2012.

P04 - Bairro Abolição (Figura 8 e 9): O abrigo meteorológico foi instalado em uma ilha artificial localizada dentro da área particular do Hotel Thermas. Esse hotel possui destaque no Rio Grande do Norte em função de suas piscinas de águas termais e pela sua localização estratégica, pois está na BR que liga as cidades de Natal/RN (270km) e Fortaleza/CE (240km). Possui algumas edificações nas proximidades. Relativo ao zoneamento urbano proposto pela PMM está localizado em uma zona urbana de densidade 


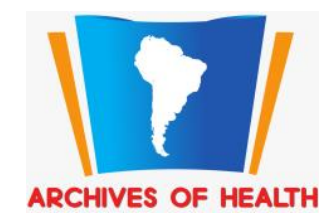

rarefeita. Nas proximidades desse ponto de coleta existem árvores e parte significativa do solo é recoberto por extrato herbáceo/arbustivo. Um fato curioso ocorreu nesse hotel: durante as primeiras perfurações de poços para o abastecimento das piscinas foi descoberto uma grande reserva de petróleo, sendo esse um dos principais acontecimentos relacionados a exploração desse recurso na cidade.

Figura 08: P04 - Abolição

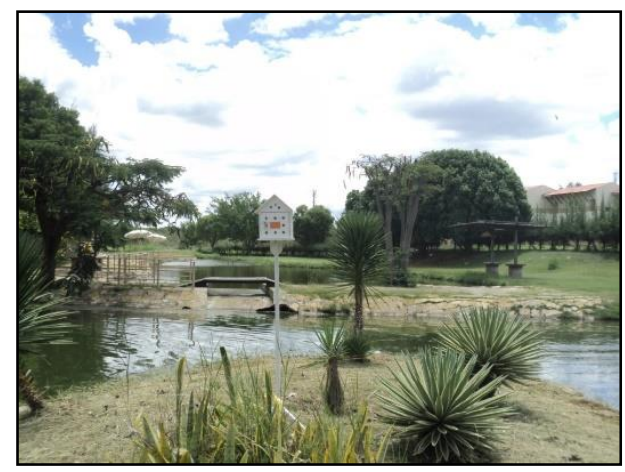

Foto: Saraiva, 2012.
Figura 09: Localização do P04

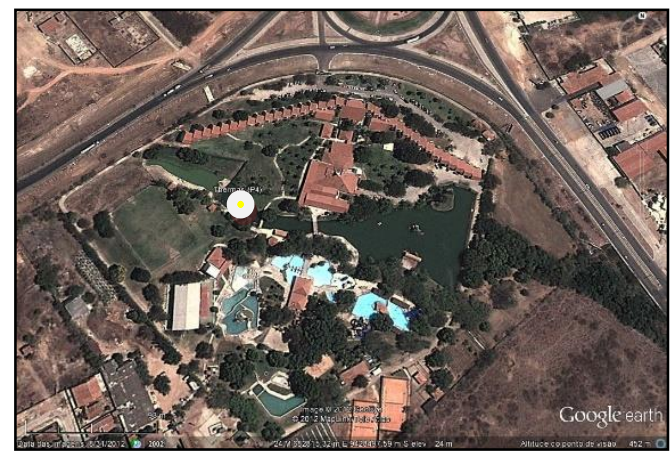

Fonte: Google Earth@, 2012.

P05 - Bairro Nova Betânia (Figura 10 e 11): Localizado na área imobiliária mais valorizada de Mossoró, dentro da área particular da Universidade Potiguar (UNP). Nas proximidades desse ponto de coleta existem poucas árvores e uma pequena parte do solo é recoberto por extrato herbáceo. Nas proximidades do ponto de coleta existe uma grande área construída e a maior parte do solo é coberta por pedras de calcário. Segundo o zoneamento urbano proposto pela Prefeitura é uma zona predominantemente residencial uni familiar e multi família. É considerada uma área adequada à expansão urbana sendo atualmente uma das áreas mais valorizadas da cidade de Mossoró, devido a sua proximidade com o shopping Mossoró West Shopping, hipermercados, condôminos de auto padrão, Universidade (UNP) e casas de alto padrão.

Figura 10: P05 - Bairro Nova Betânia

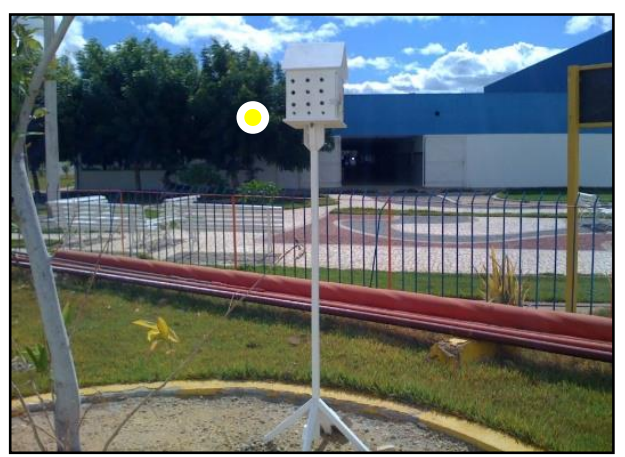

Foto: Saraiva, 2012.
Figura 11: Localização do P05

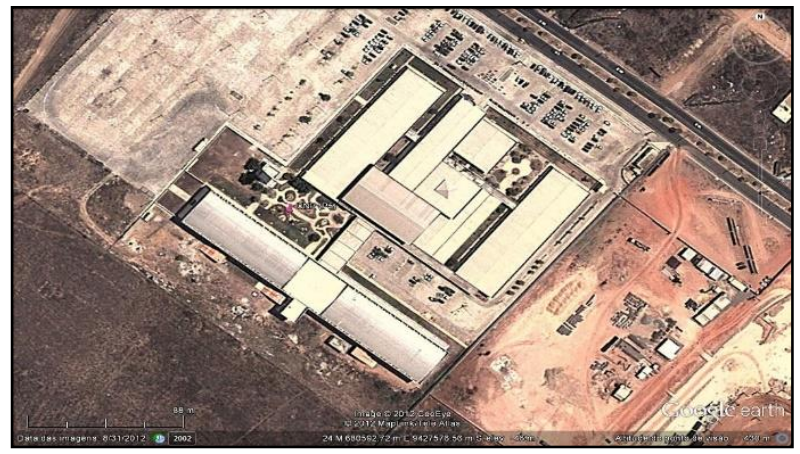

Fonte: Google Earth@, 2012.

P06 - Zona Rural: Esse ponto de coleta está localizado na Zona Rural de Mossoró, em uma propriedade privada destinada ao plantio de frutas tropicais. A área onde está localizada a estação possui 
solo exposto, com alguns remanescentes de gramíneas. Ao redor da estação existem algumas edificações, com árvores nas proximidades. A estação meteorológica pertence ao Instituto Nacional de Meteorologia INMET e foi instalada nesse local em 2007. Ela faz parte do conjunto de Estações Meteorológicas de Observação de Superfície Automática existente no Brasil, em que cada estação possui um datalogger que registra as informações dos diferentes elementos climáticos. Essas informações são disponibilizadas gratuitamente todos os dias no portal do INMET, ficando disponível por 90 dias na web (BRASIL, 2011).

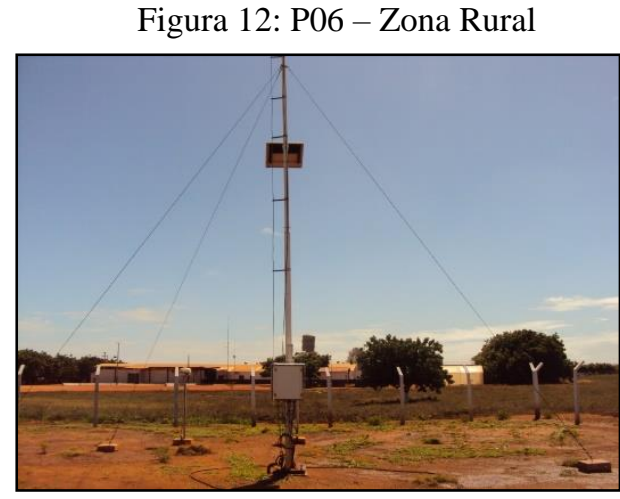

Foto: Saraiva, 2012.
Figura 13: Localização do P06

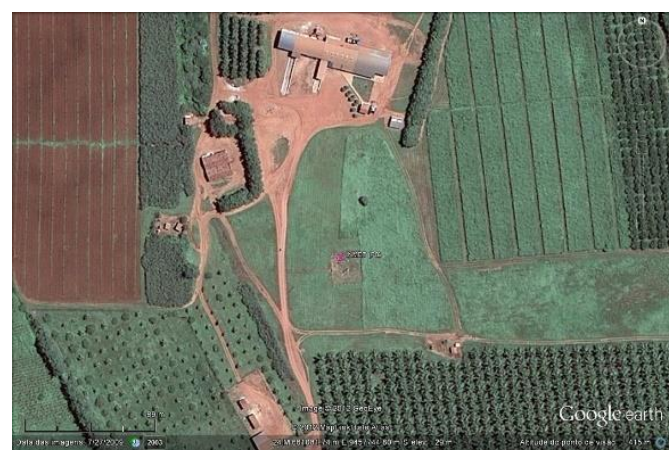

Fonte: Google Earth@, 2012.

\subsection{ANÁLISE CLIMÁTICA DO DIA ESTUDADO}

No dia 11 de abril de 2012 foram coletados dados de temperatura do ar e de umidade relativa do ar em seis locais diferentes de Mossoró, sendo cinco na zona urbana e um na zona rural. Os dados coletados nos pontos estudados são apresentados nas Figura 14 e Figura 15.

Figura 14 - Distribuição horária da temperatura do ar em Mossoró-RN no dia 11-04-2012.

\begin{tabular}{|c|c|c|c|c|c|c|c|c|c|c|}
\hline \multirow[b]{3}{*}{ P01 } & \multirow[b]{2}{*}{$8 \mathrm{~h}$} & \multicolumn{9}{|c|}{ Horários de Coleta } \\
\hline & & 9h & $10 \mathrm{~h}$ & $11 \mathrm{~h}$ & $12 \mathrm{~h}$ & $13 \mathrm{~h}$ & $14 \mathrm{~h}$ & $15 \mathrm{~h}$ & $16 \mathrm{~h}$ & $17 \mathrm{~h}$ \\
\hline & 26,7 & 28,3 & 29,4 & 30,7 & 32,1 & 32,8 & 33,3 & 32,6 & 31,1 & 30,3 \\
\hline P02 & 27,5 & 29,8 & 31,5 & 32,9 & 34,2 & 35,7 & 36,2 & 35,3 & 32,5 & 30,7 \\
\hline P03 & 27,4 & 29,3 & 31,5 & 33,4 & 35,2 & 35,8 & 36,8 & 35,1 & 33,1 & 31,5 \\
\hline P04 & 27,0 & 28,9 & 30,1 & 31,5 & 32,6 & 33,5 & 34,1 & 33,1 & 31,2 & 29,8 \\
\hline P05 & 27,8 & 30,0 & 31,7 & 32,9 & 34,0 & 35,1 & 35,7 & 35,1 & 32,6 & 30,5 \\
\hline P06 & 27,2 & 28,7 & 29,7 & 31,0 & 32,3 & 31,6 & 32,2 & 31,4 & 29,9 & 28,4 \\
\hline
\end{tabular}

Fonte de dados: Saraiva,2014.

Figura 15 - Distribuição horária dos valores de umidade relativa do ar para Mossoró-RN no dia 11-04-2012. 


\begin{tabular}{|llllllllllll|}
\hline & \multicolumn{1}{c}{} & $\mathbf{8 h}$ & 9h & 10h & 11h & $\mathbf{1 2 h}$ & 13h & $\mathbf{1 4 h}$ & $\mathbf{1 5 h}$ & $\mathbf{1 6 h}$ & 17h \\
\hline P01 & $\mathbf{7 8 , 3}$ & 67,3 & 60,5 & 48,8 & 41,7 & 38,9 & 41,7 & 45,7 & 49,9 & 59,2 \\
P02 & 65,2 & 52,8 & 46,6 & 39,2 & 31,5 & 28,1 & 29 & 34,5 & 44 & 56,8 \\
P03 & 67,3 & 57 & 48,8 & 41,5 & 31,9 & 31,1 & 31,3 & 36,1 & 42,9 & 54,5 \\
P04 & 69,4 & 58,7 & 55,3 & 46,6 & 42,1 & 38,3 & 39,3 & 43,6 & 49,3 & 58,9 \\
P05 & 66,4 & 53,7 & 45,4 & 36,3 & 26,5 & 23,4 & 20,8 & 28 & 38,8 & 54,4 \\
P06 & 70 & 61 & 55 & 51 & 47 & 51 & 50 & 49 & 58 & 70 \\
\hline
\end{tabular}

Fonte de dados: Saraiva,2014.

As temperaturas ficaram entre $26,7^{\circ} \mathrm{C}$, coletada no $\mathrm{P} 01$ às $8 \mathrm{~h}$, e $36,8^{\circ} \mathrm{C}$, coletada no $\mathrm{P} 03$ às $14 \mathrm{~h}$. As temperaturas mais elevadas foram coletadas entre às 12h e às 15h. O P01 e o P06 foram os que apresentaram ao longo do dia os menores valores de temperatura do ar. Esses pontos apresentam árvores na proximidades, pequeno fluxo de pessoas e carros nas proximidades além de área livre significativa. A amplitude térmica horaria registrada as $14 \mathrm{~h}$ foi de $4,6^{\circ} \mathrm{C}$. Já a amplitude térmica intra-urbana foi de $3,5^{\circ} \mathrm{C}$

Já os valores de umidade relativa do ar ficaram entre 78,3\%, coletado no P01 às 8h classificado pela OMS como recomendado à saúde humana, e 20,8\% coletada às 14h no P05 classificado pela OMS com Não recomendado a Saúde humana - Estado de Atenção. Os valores de umidade relativa do ar apresentam resultados preocupantes, uma vez que entre às $11 \mathrm{~h}$ e $16 \mathrm{~h}$ todos os pontos de coleta apresentaram valores abaixo do recomendado para a saúde humana pela OMS. A amplitude higrométrica encontrada às 14 h entre os pontos estudados foi de 29,2\%. Já a amplitude intraurbana foi de 20,9\%.

As amplitudes térmicas e higrométricas encontradas durante o dia estudado demonstram que as características locais podem interferir diretamente no comportamento dos elementos climáticos. Em climas semiáridos, onde os valores de temperatura podem ser cada vez mais elevados e a umidade relativa do ar pode ser ainda mais baixos em virtude das caracteríscas do uso e ocupação da terra, é necessário incluir a temática conforto térmico humano no planejamento urbano.

\subsection{CONFORTO TÉRMICO, PERCEPÇÃO E IMPACTOS NA SAÚDE HUMANA}

Foram realizadas 40 entrevistas no dia 11 de abril de 2012 das 08 h às 17 h. Foram entrevistadas 17 mulheres e 23 homens, com idade entre 18 e 85 anos para mulheres, 16 e 58 para homens entrevistados. Do total dos entrevistados 26 foram entrevistados na Praça do Mercado - Praça 1, sendo 13 mulheres e 13 homens, e 14 foram entrevistados na Praça da Catedral - Praça 2, sendo 4 mulheres e 10 anos.

As características do tempo atmosférico que mais agradam os entrevistados são: dias com temperaturas mais baixas, dias chuvosos, dias com vento forte e dias com muita nebulosidade.

Sobre existirem de locais na cidade de Mossoró que são mais agradáveis e locais mais desagradáveis do ponto de vista do conforto os entrevistados 12 pessoas destacaram que não existe diferença na cidade. 
Já 28 pessoas apontaram que na cidade de Mossoró existe uma diferença, onde é possível perceber as diferenças de temperatura do ar.

De modo geral, os entrevistados que afirmaram que existem diferenças térmicas destacaram que o bairro Centro apresenta as mais elevadas temperaturas por possuir muitos prédios, ruas asfaltadas e poucas árvores. Já bairros periféricos que possuem casas com quintais arborizados e praças muitas árvores apresentam temperaturas menores, sendo assim mais confortáveis que o centro da cidade. Esses relatos coincidem com os resultados alcançados no dia da pesquisa, onde foram coletados dados de temperatura do ar e umidade relativa do ar em diferentes pontos de Mossoró.

Das 40 pessoas entrevistadas 33 afirmaram, sendo 17 mulheres e 16 homens, que sentem sintomas desagradáveis em virtude do calor, destacando a ocorrência de dor de cabeça, mal estar, stress, cansaço, tontura e desconforto. Nas respostas era comum cada entrevistado pontuar mais de um sintoma.

Quando questionados sobre a adoção de medidas para driblar os impactos negativos do calor, 30 confirmaram que possuem práticas cotidianas que objetivam melhorar o conforto e o bem estar. Os entrevistados que afirmaram possuir essas práticas destacaram, principalmente, o uso do protetor solar e uso de boné, o uso de sombrinhas e a prática de ingerir líquidos.

Ao final das entrevistas as pessoas eram questionadas sobre qual medida ou quais medidas poderiam ser tomadas para amenizar os impactos negativos das altas temperaturas do ar e a baixa umidade relativa do ar e tornar de Mossoró uma cidade mais agradável do ponto de vista do conforto térmico. Dos 40 entrevistados 20 pessoas apontaram o plantio de árvores e a manutenção de áreas verdes como uma importante estratégia para tornar a cidade mais confortável.

\section{CONSIDERAÇÕES FINAIS}

Após a análise das temperaturas no município de Mossoró foi possível que as temperaturas mais elevadas foram detectadas entre às $12 \mathrm{~h}$ e às $15 \mathrm{~h}$, sendo o P02 - Bairro Centro e o P03 - Bairro Santo Antônio os locais que apresentaram os mais altos registros. Esses também foram os intervalos horários e os pontos de coleta de dados onde foram registrados os mais baixos valores de umidade relativa do ar.

Associaram-se os resultados obtidos aos padrões de uso e ocupação da terra das áreas estudadas. Visto que as características da área urbana (pouca cobertura vegetal, grande quantidade de prédios, áreas asfaltadas e praças que utilizam materiais incoerentes com a realidade climática da cidade, como bancos de granito e mármore) que influenciam nas altas temperaturas e nos baixos valores de umidade relativa do ar, diferente da zona rural e de áreas urbanas bem arborizadas e com disponibilidade hídrica, como no P01 Bairro Ilha de Santa Luzia e P04 - Bairro Abolição.

O comportamento dos elementos climáticos temperatura do ar e umidade relativa do ar estão diretamente associados ao conforto térmico da população. Destacamos que os pontos de coleta P02 - Bairro 
Centro e o P03 - Bairro Santo Antônio foram citados pelos entrevistados como referencias de locais quentes e desconfortáveis na cidade de Mossoró.

Relacionado a influencia do forte calor sobre ao bem-estar e a saúde, uma parcela significativa de pessoas entrevistadas afirmara sentir sintomas indesejável gerados pelas altas temperaturas do ar e pela baixa umidade relativa do ar, principalmente entre às $12 \mathrm{~h}$ e $15 \mathrm{~h}$, sendo os principais sintomas dor de cabeça, mal estar, stress, cansaço, tontura e desconforto.

É preocupante o número de pessoas que afirma não possuir nenhum hábito que busque driblas os efeitos negativos das altas temperaturas do ar, da baixa umidade relativa e da radiação solar. Sabe-se que a exposição diária a radiação solar pode prejudicar a saúde, gerando desde um desconforto passageiro até um problema de pele mais sério, como o câncer de pele

Sobre as possíveis sugestões para pensar a cidade de Mossoró como uma cidade mais confortável a arborização apareceu como principal estratégia para diminuir as temperaturas locais. Os entrevistados afirmaram que de modo geral a cidade ainda possui poucas ruas arborização e que as praças não possuem a área arborizada necessária, o que gera níveis de conforto diferentes na cidade.

Esse trabalho realizou uma investigação inicial sobre as características climáticas de Mossoró e a sua relação com a saúde da população. Diante da importância dessa temática para cidades caracterizadas por clima semiárido pretende-se realizar outras investigações sobre essa temática. 


\section{REFERÊNCIAS}

AB'SABER, N.A. 1994. No domínio das caatingas. Em pp. 37-46, S. Monteiro e L. Kaz (eds.), Caatinga. Rio de Janeiro: Livro arte Editora.

ARAÚJO, R. R. O conforto térmico e as implicações na saúde: uma abordagem preliminar sobre os seus efeitos na população urbana de São Luís-Maranhão. Cadernos de Pesquisa, v. 19, p. 51, 2012.

ANDRADE, H. O clima urbano: natureza, escalas de análise e aplicabilidade. Finisterra - Revista Portuguesa de Geografia, XL (80), 2005, p. 67 - 91.

LOMBARDO, M. A. Ilha de calor nas metrópoles: o exemplo de São Paulo. Ed. Hucitec, São Paulo, 1985.

MELO, E. C. P. Saúde e doenças no Brasil: como analisar os dados epidemiológicos. $7^{\circ}$ reimp. Rio de Janeiro: Senac Nacional. 2009. 96 p.II.

MENDONÇA, F.; DANNI-OLIVEIRA, I. M. Climatologia: noções básicas e climas do Brasil. São Paulo: Oficina de Textos, 2007.

OMS, Actas Oficiales de La OMS. $\mathrm{n}^{\circ} \quad 2012 . \quad$ Disponível em http://www.who.int/library/collections/historical/es . Acesso 21/10/2013

ONO, H. S. P.; KAWAMURA T. (1991). Sensible Climates in Monsoon Asia. Int.J. Biometeor., Vol. 35, $\mathrm{n}^{\circ} \mathrm{XX}, \mathrm{pp} .39-47$.

OKUMO, E.; m. A. C. Vilela. Radiação ultravioleta: características e efeitos. $1^{\circ}$ Ed. São Paulo: Editora Livraria da Física: Sociedade Brasileira de Física, 2005.

RIBEIRO, H. (Org). Olhares Geográficos: meio ambiente e saúde. SENAC, 2004.

SARAIVA, A. L. B. C. O clima urbano de Mossoró(RN): o subsistema termodinâmico. Dissertação Mestrado em Geografia. Vitória: Universidade Federal do Espírito Santo. 2014. 234p.

SARAIVA, A. L. B. C. A natureza cíclica do clima: uma leitura do ritmo climático no semiárido potiguar - Mossoró/RN. Assú/RN. No prelo. 2020. 